\title{
Human Immunodeficiency Virus Unknown
}

National Cancer Institute

\section{Source}

National Cancer Institute. Human Immunodeficiency Virus Unknown. NCI Thesaurus.

Code C160675.

Indicates that human immunodeficiency virus status of a sample is unknown. 